\title{
Are Standards Always Protectionist?
}

\author{
Stéphan Marette and John C. Beghin
}

Working Paper 07-WP 450

June 2007

\section{Center for Agricultural and Rural Development \\ lowa State University \\ Ames, lowa 50011-1070 \\ www.card.iastate.edu}

Stéphan Marette is with the UMR Economie Publique, Institut National de la Recherche Agronomique (INRA), France, and is a visiting scholar at the Center for Agricultural and Rural Development (CARD) at lowa State University. John Beghin is a professor of economics at lowa State University and visiting professor at the University of Sydney, Australia.

This paper is available online on the CARD Web site: www.card.iastate.edu. Permission is granted to excerpt or quote this information with appropriate attribution to the authors.

Questions or comments about the contents of this paper should be directed to Stéphan Marette, e-mail: marette@iastate.edu or marette@inapg.fr. 


\begin{abstract}
We analyze the effects of a domestic standard that reduces an externality associated with the consumption of the good targeted by the standard, using a model in which foreign and domestic producers compete in the domestic good market. Producers can reduce expected damage associated with the externality by incurring a cost that varies by source of origin. Despite potential protectionism, the standard is useful in correcting the consumption externality in the domestic country. Protectionism occurs when the welfare-maximizing domestic standard is higher than the international standard maximizing welfare inclusive of foreign profits. The standard is actually anti-protectionist when foreign producers are much more efficient at addressing the externality than are domestic producers. Possible exclusion of domestic or foreign producers arises with large standards, which may alter the classification of a standard as protectionist or non-protectionist. The paper provides important implications for the estimation and use of tariff equivalents of nontariff barriers.
\end{abstract}

Keywords: externality, nontariff barriers, protectionism, safety, standard, tariff equivalent. 


\section{Introduction}

We analyze the effects of an optimum domestic standard that reduces an externality associated with the consumption of the good targeted by the standard, using a model in which foreign and domestic producers compete in the domestic good market. Producers can reduce the expected damage associated with the consumption externality by incurring a cost that varies by source of origin. Despite potential protectionism, the standard is useful in correcting the consumption externality in the domestic country. Protectionism occurs when the welfare-maximizing domestic standard is higher than the international standard maximizing welfare inclusive of foreign profits. Anti-protectionism is the converse case. The domestic standard can be anti-protectionist when foreign producers are much more efficient at addressing the externality than are domestic producers.

Guaranteeing products' safety or environmental friendliness to consumers is challenging for many industries offering products such as aircrafts, cars, food, chemical products, or oil transportation. Limited care and control in design or manufacture of goods can result in failures of these goods with significant damages (e.g., from oil spills, food poisoning, and aircraft failures). This issue is extremely sensitive in the context of globalization where producers are located in many countries and sometimes impose very different regulations. The need for regulation may be very important when consumers (or environmentalists) cannot be certain of a product's origin, which is the case when products from a variety of processors and countries are sold at the retail level with no brand designation (Beghin and Bureau, 2001).

The implementation of the Uruguay Round of the World Trade Organization (WTO), in particular, the Sanitary and Phytosanitary (SPS) and Technical Barriers to Trade (TBT) Agreements, has provided significant momentum towards the use of international standards. 
Increased notification requirements for both TBT and SPS regulations and the desire to avoid WTO dispute settlement procedures are making countries more thoughtful about the international impacts of their regulations aimed at protecting human, animal, and plant health. A number of disputes involving several OECD countries have already been brought before the WTO since the dispute settlement procedure was established in 1995 (Dee and Ferrantino, 2005).

Government intervention is often required to protect consumers and the environment by guaranteeing that products internalize safety and environmental concerns. However, governments may use regulations as potential nontariff barriers (NTB) or even as a way to drive out foreign producers, particularly producers coming from some developing countries (Baldwin, 1970). This is the case, for instance, with many food products unable to enter the European Union unless they obtain EU certification. This problem is sensitive when farmers from developing countries cannot meet some standard requirements that farmers in developed countries can meet. The main reasons are limited access to capital (refrigerators for the example of food safety; pesticide management tools for the example of the environment) a certification process, or qualified labor (Henson and Wilson, 2005). Even if a standard is welfare enhancing, it may restrict trade because of producers' heterogeneity in terms of meeting these safety/environmental costs.

We analyze the impact of producers' heterogeneity on the standard selected by a domestic policy maker to address the safety or environmental externality. We investigate the potential protectionist impact of the standard. We focus on the choice of products' or environments' safety standard influencing both domestic and foreign producers selling in the domestic market. In a partial equilibrium model, competitive producers can increase the 
probability of reducing the expected damage associated with the externality by incurring a cost that differs according to their foreign/domestic origin. The standard consists of determining a minimum level of reduction in the expected damage (e.g., a residue level or a tolerance level) with which all sellers should comply in offering their products.

The domestic standard is selected by a policy maker seeking to maximize welfare defined by the sum of the producers' profits and consumers' surplus. The domestic standard may also influence producers' exit because of relatively large costs of meeting the targeted safety improvement. As in Fisher and Serra (2000), this domestic standard is compared to the international standard that a social planner would have implemented if it had been designed for domestic purposes (i.e., all firms are domestic firms or all agents belong to a single economy). The latter definition is considered as non-protectionist (Fisher and Serra, 2000) since it could be compared to standards defined at the international level, such as the $F A O / W H O$ Codex Alimentarius or $W H O$ medical standards.

We show that the domestic standard relative to an international standard is not always protectionist and can be anti-protectionist, implicitly subsidizing imports. In particular, a situation with much more efficient foreign producers compared to domestic producers leads to a lower domestic standard compared to the international one that would be chosen by a regulator, taking into account foreign producers in the welfare optimization. In addition, a situation with very inefficient foreign producers leads to the exclusion of the latter under both domestic and international standards.

However, when the safety cost of foreign producers is either near or higher than the safety cost of domestic producers, the domestic standard is protectionist. What we mean by near is explained more precisely later in the modeling section. Moreover, when domestic producers 
are very inefficient and the damage is relatively large, domestic producers may be driven out of the market (despite the absence of sunk cost in our model). The regulator imposes a domestic standard that is larger than the international one, since foreign producers incur a large part of the safety cost (that is passed onto consumers). In this case, protectionism emerges without a motive, as domestic producers exit the market, and the domestic standard obviously fails to protect domestic producers.

The paper also derives new and important implications on the estimation and use of tariff equivalents for nontariff measures. The tariff equivalent is the price effect equivalent to the impact of the nontariff policy, in our case, a standard. We show that the computation of tariff equivalents is more complex than generally assumed (Deardorff and Stern, 1998), in particular when domestic or foreign producers can be driven out of the market. In other words, producers' exclusion leads to discontinuities in tariff equivalent and even a shift in the sign of this tariff equivalent when less-efficient domestic producers leave the market. Finally, protectionist implications often derived in simple tariff-equivalent measures abstracting from the international standard could be seriously misleading.

Our paper contributes to the TBT literature. Most of this literature has been empirical (see Deardorff and Stern, 1998, and Yue, Beghin, and Jensen, 2006) with very few analytical contributions, with the notable exception of Fisher and Serra, 2000. Our paper departs from the literature on standards in international trade, which has overlooked the important consequences of heterogeneity in safety cost. In particular, our results differ from and qualify Fisher and Serra's (2000) main conclusion that, in the presence of a consumption externality, the standard chosen by the social planner is always protectionist. Conversely, we show that this previous result is less general than originally thought, because of potentially large safety cost 
heterogeneity between domestic and foreign producers. In the latter case, the domestic standard is not systematically protectionist and can be anti-protectionist. Note that our results do not depend on any impact of quality on demand since the externality does not lead to any demand shifts, which crucially differs from the studies of Das and Donnenfeld (1987 and 1989);

Chambers and Weiss (1992); Boom (1995); Bureau, Marette, and Schiavina (1998); Tian (2003); and Sturm (2006). Nevertheless, our results are robust to relaxing the latter assumption and allowing for this interaction. The interaction induces a multiplicity of cases but does not invalidate the essential point that an optimum domestic standard may not be protectionist.

Further, our results do not depend on the incentive to be more competitive by lowering environmental standards to reduce products costs and become more competitive in foreign markets, as in Barrett (1994), since we do not consider any foreign market. The selection of a domestic standard that is lower than the international one comes only from considerations about safety cost heterogeneity, without any strategic views for capturing potential market share on foreign markets.

In the next section, we introduce the stylized model. Then we explain the market equilibrium and regulatory choice. Finally, we present some extensions and conclusions.

\section{Model}

We use a sparse and stylized framework in which trade occurs in a single period with domestic producers and foreign producers in a competitive market for good $x$. Extensions are discussed later. The ability to offer reliable products is determined by a combination of producers' effort and randomness. Reliability may concern products’ safety or environmental cleanliness. The 
producers' ability to reduce risks depends on their effort and input decisions (new technologies or improvements in labor training) but remains to some degree imperfect.

For simplicity, we let a producer's effort be equivalent to the probability of a safe product emerging (making the probability a function of the effort just adds unnecessary complications for our purpose). With a probability $0 \leq \lambda \leq 1$, a producer only offers safe products and with a probability $(1-\lambda)$, a producer only offers unsafe products. The level of care $0 \leq \lambda \leq 1$ comes about through a variable cost $c \lambda^{2}$ for a domestic producer and through a variable cost $\gamma c \lambda^{2}$ for a foreign producer with $\gamma>0$. This parameter $\gamma$ captures natural, technological, organizational, or institutional advantage with $\gamma<1$ for a foreign producer (respectively disadvantaged with $\gamma>1$ ). There is also a variable cost not depending on the safety effort, $x^{2} / 2$, whatever the origin, where $x$ is the producer's output. We assume that producers are price takers. For each county, there are a large number of producers, each of them with zero mass individually, but with aggregate mass normalized to one for simplicity. The total costs for domestic and foreign outputs $x_{d}$ and $x_{f}$ are, respectively, $c \lambda^{2} x_{d}+x_{d}^{2} / 2$ and $\gamma c \lambda^{2} x_{f}+x_{f}^{2} / 2$.

For simplicity, a linear demand $x(p)=a-p$ in the domestic country is considered, where $a$ is a positive parameter indicating the maximum market size, and $p$ is the price. All foreign production is exported to the domestic market. The expected external damage associated with the consumption of $x$ is $-\left[x_{d}\left(1-\lambda_{d}\right)+x_{f}\left(1-\lambda_{f}\right)\right] k$, where $x_{d}$ and $x_{f}$ are domestic and foreign components of domestic consumption and $1-\lambda_{d}$ and $1-\lambda_{f}$ are the domestic and foreign probability of having unsafe products. Parameter $k$ is a measure of the per-unit external damage. This damage does not influence the consumers' choices, since we assume that damage and market decision are separable. This potential injury may correspond to an environmental damage 
(see Freeman, 2003, p. 122) or to a safety damage directly linked to a product affecting unaware consumers at the time of the purchase (see Polinsky and Rogerson, 1983). The expected external damage is taken into account in the welfare by the regulator.

The regulator may select a mandatory standard. This "reliable product" standard corresponds to a minimum level of effort $\lambda$ imposed on all producers offering products on the domestic market. The mandatory standard is selected by a domestic regulator searching to maximize domestic welfare defined by the sum of the domestic producers' profits, the domestic consumers' surplus, and the expected external damage.

To determine the existence or the absence of protectionism, this domestic standard is compared with the international standard, chosen to maximize international welfare, namely, the domestic welfare plus the foreign producers' profits. A higher domestic standard than an international standard is interpreted as protectionism. This definition corresponds to the Fisher and Serra's (2000, p. 389) stipulation of a non-protectionist standard equal to the standard the social planner would use if all producers were domestic.

We now turn to the description of the market equilibrium in the absence/presence of a standard.

\section{Market effects of a standard}

We first describe producers' choices. As the damages are external to the demand and profit, producers have no incentive to choose any effort for reducing this damage in the absence of regulation. Because the effort selected by producers is zero without regulation, this means that a standard is the only way to impose a positive effort $(\lambda>0)$ to reduce the risk of this external 
damage. We now turn to profits and welfare determination for a level of effort $\lambda$ imposed by the regulator.

Based on the assumption in the previous section, the respective profits for domestic and foreign producers are

$$
\left\{\begin{array}{l}
\Pi_{d}=p x_{d}-c \lambda^{2} x_{d}-x_{d}^{2} / 2 \\
\Pi_{f}=p x_{f}-\gamma c \lambda^{2} x_{f}+x_{f}^{2} / 2
\end{array} .\right.
$$

From the maximization of the profit $\Pi_{d}$, the supply curve for domestic producer is $x_{d}=p-c \lambda^{2}$. From the maximization of the profit $\Pi_{f}$, the supply curve for foreign producer is $x_{f}=p-\gamma c \lambda^{2}$. With demand $x(p)=a-p$, the market clearing process is given by $x(p)=x_{d}+x_{f}$ and leads to an equilibrium price

$$
p(\lambda)=\left(a+c \lambda^{2}+\gamma c \lambda^{2}\right) / 3
$$

The substitution of $p(\lambda)$ in quantities $x_{d}$ and $x_{f}$ leads to the equilibrium quantities $x_{d}(\lambda)=\left(a-2 c \lambda^{2}+\gamma c \lambda^{2}\right) / 3$ and $x_{f}(\lambda)=\left(a+c \lambda^{2}-2 \gamma c \lambda^{2}\right) / 3$. The selected safety standard is compatible with positive offered quantities if $x_{d}(\lambda)>0$ and $x_{f}(\lambda)>0$. This is the case if the standard $\lambda$ is lower than $\operatorname{Min}\left[\hat{\lambda}_{d}, \hat{\lambda}_{f}, 1\right]$ with

$$
\left\{\begin{array}{l}
\hat{\lambda}_{d}=\sqrt{\frac{a}{c(2-\gamma)}} \\
\hat{\lambda}_{f}=\sqrt{\frac{a}{c(2 \gamma-1)}}
\end{array}\right.
$$


corresponding to $x_{d}\left(\hat{\lambda}_{d}\right)=0$ and $x_{f}\left(\hat{\lambda}_{f}\right)=0$. If $a>c(2-\gamma)$, then $\hat{\lambda}_{d}>1$, which means that the domestic producer will always offer products for $0 \leq \lambda \leq 1$. Similarly, if $a>c(2 \gamma-1)$, then $\hat{\lambda}_{f}>1$, which means that the foreign producer will always offer products for $0 \leq \lambda \leq 1$. For $\lambda \leq \operatorname{Min}\left[\hat{\lambda}_{d}, \hat{\lambda}_{f}, 1\right]$, domestic and foreign producers offer $x_{d}(\lambda)$ and $x_{f}(\lambda)$ respectively, leading to the equilibrium profits

$$
\left\{\begin{array}{l}
\Pi_{d}(\lambda)=\frac{\left(a-2 c \lambda^{2}+\gamma c \lambda^{2}\right)^{2}}{18} \\
\Pi_{f}(\lambda)=\frac{\left(a+c \lambda^{2}-2 \gamma c \lambda^{2}\right)^{2}}{18}
\end{array} .\right.
$$

At the equilibrium, the consumers' surplus is $C S_{d}(\lambda)=\left(2 a-c \lambda^{2}-\gamma c \lambda^{2}\right)^{2} / 18$. By using the expected external damage $-\left[x_{d}\left(1-\lambda_{d}\right)+x_{f}\left(1-\lambda_{f}\right)\right] k$ of section 2 , the overall damage coming from the product is equal to $K(\lambda)=-(1-\lambda)\left(2 a-c \lambda^{2}-\gamma c \lambda^{2}\right) k / 3$. The domestic welfare, defined as the sum of producers’ profit, consumers' surplus, and the external expected damage is

$$
W_{d}(\lambda)=\Pi_{d}(\lambda)+C S_{d}(\lambda)+K(\lambda)
$$

The international welfare is defined as the sum of foreign producers' profit and domestic welfare, namely,

$$
W_{i}(\lambda)=W_{d}(\lambda)+\Pi_{f}(\lambda)
$$

Alternatively, if the standard $\lambda$ chosen by the policy maker is greater than $\operatorname{Min}\left[\hat{\lambda}_{d}, \hat{\lambda}_{f}, 1\right]$ as defined by (3), then less-efficient producers will exit the market. In this case, only the most efficient producers offer products involving two sub-cases. 
In the first sub-case, if the standard is such that $\lambda \geq \hat{\lambda}_{d}$ with $\hat{\lambda}_{d}<1$, domestic producers exit the market. From the maximization of profit $\Pi_{f}$, given by (1), the supply curve for foreign producers is $x_{f}=p-\gamma c \lambda^{2}$. The market clearing process, given by $x(p)=x_{f}$, leads to an equilibrium price

$$
\bar{p}(\lambda)=\left(a+\gamma c \lambda^{2}\right) / 2,
$$

where the upper bar indicates the value of endogenous variables under this first alternative case $\lambda \geq \hat{\lambda}_{d}$ with $\hat{\lambda}_{d}<1$. The substitution of $\bar{p}(\lambda)$ and $x_{f}$ in the profit function leads to the equilibrium profits, $\bar{\Pi}_{f}(\lambda)=\left(a-\gamma c \lambda^{2}\right)^{2} / 8$. At the equilibrium, the consumers' surplus is $\overline{C S}_{d}(\lambda)=\left(a-\gamma c \lambda^{2}\right)^{2} / 8$. The expected external damage associated with the consumption is equal to $\bar{K}(\lambda)=-(1-\lambda)\left(a-\gamma c \lambda^{2}\right) k / 2$. The domestic welfare, defined as the sum of consumers' surplus and external expected damage is

$$
\bar{W}_{d}(\lambda)=\overline{C S}_{d}(\lambda)+\bar{K}(\lambda) .
$$

The international welfare is defined as the sum of foreign producers' profit and domestic welfare, namely,

$$
\bar{W}_{i}(\lambda)=\bar{W}_{d}(\lambda)+\bar{\Pi}_{f}(\lambda) .
$$

In the second sub-case, the standard is such that $\lambda>\hat{\lambda}_{f}$ with $\hat{\lambda}_{f}<1$, the foreign producers exit the market. The most efficient producers are the domestic producers. From the maximization of the profit $\Pi_{d}$, given by (1), the supply curve for foreign producers is $x_{d}=p-c \lambda^{2}$. With a demand $x(p)=a-p$, the market clearing process, given by $x(p)=x_{d}$, leads to an equilibrium price

$$
\tilde{p}(\lambda)=\left(a+c \lambda^{2}\right) / 2
$$


where the upper tilde indicates the value of endogenous variables under this second alternative sub-case $\lambda^{s}>\hat{\lambda}_{f}$ with $\hat{\lambda}_{f}<1$. The substitution of $\tilde{p}(\lambda)$ and $x_{d}$ in the profit function leads to equilibrium profit $\widetilde{\Pi}_{d}(\lambda)=\left(a-c \lambda^{2}\right)^{2} / 8$ for domestic producers. At the equilibrium, the consumers' surplus is $\widetilde{C S}_{d}(\lambda)=\left(a-c \lambda^{2}\right)^{2} / 8$. The expected external damage associated with the consumption is equal to $\widetilde{K}(\lambda)=-(1-\lambda)\left(a-c \lambda^{2}\right) k / 2$. The domestic welfare (equal to the international welfare), defined as the sum of consumers' surplus and external expected damage is

$$
\widetilde{W}_{d}(\lambda)=\widetilde{\Pi}_{d}(\lambda)+\widetilde{C S}_{d}(\lambda)+\widetilde{K}(\lambda) .
$$

The regulator maximizes the welfare by considering a possible producers' exit. To simplify the presentation, we successively consider the case in which producers' exclusion is impossible and then the case in which producers can be excluded. Exclusion is impossible if the market is "big enough," that is, $a \geq \operatorname{Min}[c(2-\gamma), c(2 \gamma-1)]$ corresponding to $\operatorname{Min}\left[\hat{\lambda}_{d}, \hat{\lambda}_{f}\right] \geq 1$.

Producers' exclusion is possible for some values of $\operatorname{Min}\left[\hat{\lambda}_{d}, \hat{\lambda}_{f}\right] \leq \lambda \leq 1$ if $a<\operatorname{Min}[c(2-\gamma), c(2 \gamma-1)]$ corresponding to $\operatorname{Min}\left[\hat{\lambda}_{d}, \hat{\lambda}_{f}\right]<1$. This allows us to derive results specific to each case.

\section{The optimum standard in the absence of exclusion}

From section 3, exclusion of producers because of a high standard is impossible for any value of $0 \leq \lambda \leq 1$, if $a \geq \operatorname{Min}[c(2-\gamma), c(2 \gamma-1)]$. In other words, equilibrium price defined by (2) is sufficient for covering any level of effort. As producers' exclusion is impossible, the standard choices are to consider either the maximization of the domestic welfare defined by (5) for the 
domestic standard, or the maximization of the international welfare defined by (6) for the international standard. This leads us to compare the levels maximizing (5) and (6).

The first derivatives of (5) and (6) are respectively equal to

$$
\left\{\begin{array}{l}
\frac{d W_{d}(\lambda)}{d \lambda}=\frac{a[6 k-2(4 c+\gamma c) \lambda]+\lambda\left[10 c^{2} \lambda^{2}+(c+\gamma c) k(6-9 \lambda)+(\gamma c-c) 4 \gamma c \lambda^{2}\right]}{9} \\
\frac{d W_{i}(\lambda)}{d \lambda}=\frac{2 a[k-(c+\gamma c) \lambda]+\lambda\left[4 c^{2} \lambda^{2}+(c+\gamma c) k(2-3 \lambda)+(\gamma c-c) 4 \gamma c \lambda^{2}\right]}{3}
\end{array},\right.
$$

with $d^{2} W_{d}(\lambda) / d \lambda^{2}<0$ and $d^{2} W_{i}(\lambda) / d \lambda^{2}<0$. The difference between the two expressions of (12) evaluated at any arbitrary level of $\lambda$ allows us to get information about the optimal standard under both configurations. The difference between the first derivatives is given by

$$
\Delta=\frac{d W_{i}(\lambda)}{d \lambda}-\frac{d W_{d}(\lambda)}{d \lambda}=\frac{2 \lambda c(1-2 \gamma)\left[a+c(1-2 \gamma) \lambda^{2}\right]}{9} .
$$

From (13), the expression $\Delta<0$ is satisfied for $\gamma>1 / 2$, because of the assumption $a \geq \operatorname{Min}[c(2-\gamma), c(2 \gamma-1)]$ implying $a+c(1-2 \gamma) \lambda^{2}>0$ in $\Delta$ for any $0 \leq \lambda \leq 1$. The value $1 / 2$ corresponds to an upper bound regarding the cost advantage of the foreign producer and its influence on the first-derivative ranking. Thus, for $\gamma>1 / 2$, the first derivative $d W_{i}(\lambda) / d \lambda$ is lower than $d W_{d}(\lambda) / d \lambda$ evaluated at any arbitrary level of $\lambda$ as represented in Figure 1. Effort $\lambda$ is located along the horizontal axis of the figure and the first derivatives are on the vertical axis.

Figure 1 represents the first derivatives (12) derived by using the Mathematica software for values $a=10, c=2, d=3$ and $\gamma=1 .^{l}$ From Figure 1, it is easy to see that $\Delta<0$. The first-order conditions $d W_{i}\left(\lambda_{i}^{*}\right) / d \lambda=0$ and $d W_{d}\left(\lambda_{d}^{*}\right) / d \lambda=0$ define the respective welfare maximization

\footnotetext{
${ }^{1}$ All the Mathematica programs generating the five figures are available from the authors upon request.
} 
levels of $\lambda$ and lead to standards such that $\lambda_{i}^{*}<\lambda_{d}^{*}$ (note from (12) that there is no simple analytical solution). When the per-unit damage $k$ increases, the two derivatives move upwards with $d W_{i}(\lambda) / d \lambda$ still lower than $d W_{d}(\lambda) / d \lambda$, which explains why $d W_{i}(1) / d \lambda>0$ and $d W_{d}(1) / d \lambda>0$ eventually lead to $\lambda_{i}^{*}=\lambda_{d}^{*}=1$ when damage is large enough.

The expression $\Delta=0$ is satisfied for $\gamma=1 / 2$. In this case, the first derivative $d W_{i}(\lambda) / d \lambda$ is equal to $d W_{d}(\lambda) / d \lambda$ for any value $0 \leq \lambda \leq 1$, which leads to standards $\lambda_{i}^{*}=\lambda_{d}^{*}$.

The expression $\Delta>0$ is satisfied for $\gamma<1 / 2$ and $0 \leq \lambda \leq 1$, corresponding to much more competitive foreign producers relative to domestic producers, which means that the first derivative $d W_{i}(\lambda) / d \lambda$ is larger than $d W_{d}(\lambda) / d \lambda$ evaluated at any arbitrary level of $\lambda$ (namely, the opposite case from the one represented in Figure 1). The first-order conditions $d W_{i}\left(\lambda_{i}^{*}\right) / d \lambda=0$ and $d W_{d}\left(\lambda_{d}^{*}\right) / d \lambda=0$ defining the respective welfare maximizations lead to standards such that $\lambda_{i}^{*}>\lambda_{d}^{*}$.

Whatever the regulatory choice is, the entry of foreign producers is not restricted by this regulatory choice, and the equilibrium price internalizes the marginal cost of the standard. The producers simply pass on the marginal cost of the standard to consumers via the price. When the per-unit damage increases, the standards $\lambda_{d}^{*}$ and $\lambda_{i}^{*}$ increase to limit the damage impact. When the per-unit damage, $d$, is relatively large, the optimum choice consists of fully eliminating the risk with both domestic and international standards equal to one. When the damage is relatively low, situations differ according to $\Delta$ capturing the cost differences between domestic and foreign producers. 
Figure 1 and the previous developments allow us to characterize the difference between domestic and international safety standards. Based on the optimization $d W_{d}(1) / d \lambda=0$ and $d W_{i}(1) / d \lambda=0$, let's define

$$
\begin{aligned}
& k_{1}=\frac{2\left[a(4 c+\gamma c)-c^{2}\left(5-2 \gamma+2 \gamma^{2}\right)\right]}{6 a-3(c+\gamma c)} \\
& k_{2}=\frac{2\left[a(c+\gamma c)-2 c^{2}\left(1-\gamma+\gamma^{2}\right)\right]}{2 a-(c+\gamma c)} .
\end{aligned}
$$

If $k \geq k_{1}$, then $d W_{d}(1) / d \lambda>0$, and if $k \geq k_{2}$, then $d W_{i}(1) / d \lambda>0$. As no simple analytical solutions are possible, $\lambda_{d}^{*}$ and $\lambda_{i}^{*}$ are such that $d W_{d}\left(\lambda_{d}^{*}\right) / d \lambda=0$ and $d W_{i}\left(\lambda_{i}^{*}\right) / d \lambda=0$. The previous developments lead us to the following propositions 1 and 2.

PROPOSITION 1. If $\gamma<1 / 2$, the regulatory choice is to set the international standard $\lambda_{i}^{*}$ strictly greater than the domestic standard $\lambda_{d}^{*}$ if $k<k_{1}$, or to set both standards equal to one if $k \geq k_{1}$. The domestic standard $\lambda_{d}^{*}$ is non-protectionist (weakly anti-protectionist).

Proof: direct from equations (12) and (13) and Figure 1.

Figure 2 illustrates proposition 1 by using the Mathematica software for values $a=10$, $c=2$, and $\gamma=1 / 4$. The top of Figure 2 represents the optimum standards $\lambda_{d}^{*}$ and $\lambda_{i}^{*}$ maximizing (5) and (6), where the per-unit damage $k$ is located along the horizontal axis and the optimal choices $\lambda^{*}$ are located on the vertical axis. The corresponding price differences under both standards are represented at the bottom of Figure 2, where the per-unit damage $k$ is located along the horizontal axis and the price difference $p\left(\lambda_{d}\right)-p\left(\lambda_{i}\right)$ linked to standards maximizing (5) and (6) is on the vertical axis. This price difference under both standards can be interpreted as a tariff equivalent, namely, a measure of the (anti)protectionist intensity reflected in prices. The 
equilibrium price changes, with standards maximizing both domestic and international welfares since the cost of regulation is passed on to consumers. A positive value of this price difference is a measure of a possible NTB (see Deardorff and Stern, 1998, p. 16).

In proposition 1, foreign producers are much more efficient than are domestic producers, so that the domestic regulator limits the domestic safety standard that is lower than the international standard, in order to limit the cost differences $c-\gamma c$ that could hurt the domestic producers in terms of output and profits (see top of Figure 2). This result is significant, since, even if the damage does not affect the demand, a standard imposed by a country can be considered as non- or anti-protectionist. This case was overlooked by the previous literature.

For any values $\gamma<1 / 2$, the tariff equivalent is negative (i.e., an implicit import subsidy) for relatively low values of the per-unit damage $k$ since the international standard is larger than the domestic standard (see bottom part of Figure 2). The price difference $p\left(\lambda_{d}^{*}\right)-p\left(\lambda_{i}^{*}\right)$ reflects the standard differences since all the cost is passed on to the price. For a per-unit damage, $0<k<k_{2}$, the international standard increase with $d$ is higher than the domestic standard increase, which explains the decreasing slope of the price difference $p\left(\lambda_{d}^{*}\right)-p\left(\lambda_{i}^{*}\right)$. For $k>k_{2}$, the international standard reaches a maximum with $\lambda_{i}^{*}=1$ since the damage is relatively large, while the domestic standard continues to increase for $k<k_{1}$. This explains the increasing slope of the price difference $p\left(\lambda_{d}^{*}\right)-p(1)$ for $k_{2}<k<k_{1}$. For $k>k_{1}$, both domestic and international standards reach a maximum with $\lambda_{d}^{*}=1$, and all producers offer products while the damage completely disappears.

We now turn to the case in which the cost parameter is $\gamma>1 / 2$, summarized in the following proposition. 
PROPOSITION 2. If $\gamma>1 / 2$, the regulatory choices are to set the international standard $\lambda_{i}^{*}$ strictly lower than the domestic standard $\lambda_{d}^{*}$ if $k<k_{2}$, or to set both standards equal to one if $k \geq k_{2}$. The domestic standard $\lambda_{d}^{*}$ is protectionist for $k<k_{2}$.

Proof: direct from equations (12) and (13) and Figure 1.

Figure 3 illustrates proposition 2 by using the Mathematica software for the values $a=10$, $c=2$, and $\gamma=1$ (which means that the cost structure is similar for all producers). In proposition 2, domestic producers are a little less efficient (for $1 / 2<\gamma<1$ ) or more efficient (for $\gamma>1$ ) than foreign producers, so that the domestic regulator imposes a higher safety standard compared to the international standard to mitigate the expected external damage but without hurting domestic producers (see top part of Figure 3). The domestic standard could be interpreted as protectionist as it is higher than the international standard. Note that if $k<k_{2}$, the difference between both standards $\lambda_{d}^{*}$ and $\lambda_{i}^{*}$ increases when $\gamma$ increases, since a larger cost difference leads to a larger difference in standards.

For any value $\gamma>1 / 2$, the tariff equivalent is positive for relatively low-values of the perunit damage $k$ since the international standard is lower than the domestic standard (see bottom part of Figure 3). The price difference $p\left(\lambda_{d}^{*}\right)-p\left(\lambda_{i}^{*}\right)$ reflects the difference in standards since all the cost is passed on in the price. For a per-unit damage, $0<k<k_{1}$, the international standard increases with $k$ but not as much as the domestic standard does. The latter explains the increasing slope of the price difference $p\left(\lambda_{d}^{*}\right)-p\left(\lambda_{i}^{*}\right)$. For $k>k_{1}$, the domestic standard reaches a maximum with $\lambda_{d}^{*}=1$ since the damage is relatively large, while the international standard continues to increase for $k>k_{1}$. This explains the decreasing slope of the price difference 
$p(1)-p\left(\lambda_{i}^{*}\right)$ for $k_{1}<k<k_{2}$. For $k>k_{2}$, both domestic and international standards reach a maximum with $\lambda_{i}^{*}=1$, and all producers offer products while the damage completely disappears.

From the two previous propositions, we note that protectionism is more likely to emerge when damages are low and when domestic producers are better (or at least not much worse) at meeting the standard than are foreign producers. Hence, the conditions for protectionism to emerge are more contrived than it appears at first glance, raising the issue of potential overstatement of protectionism in policy debates and the literature.

\section{The optimum standard under possible exclusion}

We now turn to configurations where some producers may exit the market following the imposition of a standard. Exclusion (or exit) is widespread for developing countries that sometimes lack private and/or public capital for satisfying some safety requirements. For instance, the European Commission has recently adopted a blacklist of airlines, which are banned in the European Union for lack of safety (EC, 2006). It means that the safety standards are lower for some foreign countries compared to those of the European Union.

Under the assumptions of section 2, exclusion is possible for relatively large values of $0 \leq \lambda \leq 1$ if $a<\operatorname{Max}[c(2-\gamma), c(2 \gamma-1)]$ corresponding to $\operatorname{Min}\left[\hat{\lambda}_{d}, \hat{\lambda}_{f}\right]<1$ (see equation (3)). Under exclusion, various regulatory choices maximize welfares defined by (8), (9), or (11). We respectively distinguish the case for which the exclusion of the domestic producer is possible from the one for which the exclusion of the domestic producer is not possible. 


\subsection{Possible exclusion of domestic producers}

If the standard is such that $\lambda \geq \hat{\lambda}_{d}$ with $\hat{\lambda}_{d}<1$ corresponding to $a<c(2-\gamma)$, domestic producers exit the market. Only foreign producers offer products (see equations (7), (8), and (9) in section 3). Figure 4 represents the standard choice (top part) and the corresponding tariff equivalent (bottom part) generated with the Mathematica software for values $a=10, c=10$, and $\gamma=2 / 5$. This last value means that foreign producers are more efficient than the domestic producers regarding the ability to comply with any standard. There is no simple analytical solution for the different frontiers $k_{3}$ to $k_{6}$ on the horizontal axis.

If $k<k_{3}$, the per-unit damage is relatively low, which explains relatively low standards maximizing (5) or (6). All producers produce since both optimum standards $\lambda_{d}^{*}$ and $\lambda_{i}^{*}$, the solutions of $d W_{d}\left(\lambda_{d}^{*}\right) / d \lambda=0$ and $d W_{i}\left(\lambda_{i}^{*}\right) / d \lambda=0$, are lower than the threshold $\hat{\lambda}_{d}$ above which domestic producers exit the market. The international standard $\lambda_{i}^{*}$ is higher than the domestic standard $\lambda_{d}^{*}$ for the same reasons as in proposition 1 since $\gamma=2 / 5<1 / 2$. The tariff equivalent is negative, since the international standard is larger than the domestic standard (see bottom part of Figure 4). This is an anti-protectionist situation.

If $k \geq k_{3}$, a domestic standard equal to one leads to the exclusion of domestic producers. In this case the domestic welfare $W_{d}\left(\lambda_{d}^{*}\right)$, given by (5) with an effort $\lambda_{d}^{*}$ and with all producers, is strictly lower than the domestic welfare $\bar{W}_{d}(1)$, given by (8) with an effort equal to one but without domestic producers. ${ }^{2}$ In other words, the benefit of eliminating the expected external

\footnotetext{
${ }^{2}$ The value $k_{3}$ is determined by $W_{d}\left(\lambda_{d}^{*}\right)=\bar{W}_{d}(1)$. For $k<k_{3}$, the inequality $W_{d}\left(\lambda_{d}^{*}\right)>\bar{W}_{d}(\lambda)$ is satisfied for any $0 \leq \lambda \leq 1$. For $k>k_{3}$, the inequality $d \bar{W}_{d}(1) / d \lambda>0$ is satisfied, which leads to a regulatory choice equal to one.
} 
damage with $\bar{K}(1)=0$ (see section 3 ) outweighs the economic loss linked to the exclusion of domestic producers.

If $k_{3} \leq k<k_{6}$, the domestic standard equal to one becomes protectionist since it is higher than the international optimum standard. The latter takes on values equal to $\lambda_{i}^{*}$ if $k_{3} \leq k<k_{4}$, to $\hat{\lambda}_{d}$ if $k_{4} \leq k<k_{5}$, and to $\bar{\lambda}_{i}^{*}$ if $k_{5} \leq k<k_{6}{ }^{3}$ In this case, "protectionism" emerges even if domestic producers exit the market, and the domestic purpose is obviously not to protect domestic producers but rather to eliminate the expected external damage $\bar{K}(1)=0$. Even if the cost of meeting the standard $\gamma c \lambda^{2}$ is passed on to consumers, foreign producers bear a significant part of this cost. This explains why the international standard maximizing (6) or (9) including the foreign producers’ profits is lower than a domestic standard maximizing (8) without domestic producers. If $k_{3} \leq k<k_{4}$, the domestic standard equal to one leads to the exclusion of the domestic industry, while the international standard equal to $\lambda_{i}^{*}<\hat{\lambda}_{d}$ allows the presence of domestic producers. This is a counterintuitive result since a domestic country imposes the exit of domestic producers compared to an international standard allowing domestic producers. If $k \geq k_{4}$, both standards lead to the exclusion of domestic producers. For $k \geq k_{6}$, both domestic and international standards reach a maximum equal to one with only foreign producers offering products.

\footnotetext{
${ }^{3}$ If $k_{3} \leq k<k_{4}$, the international welfare $W_{i}\left(\lambda_{i}^{*}\right)$ given by (6) with an effort $\lambda_{i}^{*}$ and with all producers is strictly higher than international welfares $\bar{W}_{i}\left(\hat{\lambda}_{d}\right)$ or $\bar{W}_{i}\left(\bar{\lambda}_{i}^{*}\right)$ with $\bar{\lambda}_{i}^{*}$ such that $d \bar{W}_{i}\left(\bar{\lambda}_{i}^{*}\right) / d \lambda=0$ and $\bar{W}_{i}$ given by (9) without domestic producers. If $k \geq k_{4}, \bar{W}_{i}\left(\bar{\lambda}_{i}^{*}\right)>W_{i}\left(\lambda_{i}^{*}\right)$, but $\bar{\lambda}_{i}^{*}<\hat{\lambda}_{d}$. As $d^{2} W_{i}(\lambda) / d \lambda^{2}>0$ for any level of $0 \leq \lambda \leq \hat{\lambda}_{d}$, the level $\hat{\lambda}_{d}$ defined by (3) is selected and it leads to the exclusion of domestic producers. For $k \geq k_{5}$, the inequality $\bar{\lambda}_{i}^{*} \geq \hat{\lambda}_{d}$ is satisfied leading to an international standard equal to $\bar{\lambda}_{i}^{*}$.
} 
Regarding the corresponding tariff equivalent (see bottom of Figure 4), there is a discontinuity since the equivalent is negative (i.e., an implicit import subsidy) if $k<k_{3}$, and positive (i.e., an implicit import tax) if $k_{3} \leq k<k_{6}$ because of the exclusion of domestic producers (with $\bar{p}(\lambda)$ defined by (7)). Clearly, this effect should be taken into account in all empirical measures of nontariff barriers, since having more efficient foreign producers compared to domestic ones does not necessary imply the absence of protectionism. A domestic regulator may be tempted to impose a higher standard compared to the international standard when domestic producers exit the market.

\subsection{Possible exclusion of foreign producers}

If the standard is such that $\lambda \geq \hat{\lambda}_{f}$ with $\hat{\lambda}_{f}<1$ corresponding to $a<c(2 \gamma-1)$, foreign producers exit the market. Only domestic producers offer products (see equations (10) and (11) in section 3). Figure 5 represents the optimal standard (at the top) and the tariff equivalent (at the bottom), also generated by the Mathematica software for values $a=10, c=4$, and $\gamma=15 / 2$.

If $k<k_{6}$, there is no exclusion of foreign producers. The per-unit damage $k$ is relatively low, which explains relatively low standards maximizing (5) or (6). The domestic standard $\lambda_{d}^{*}$ is higher than the international standard $\lambda_{i}^{*}$ (the interpretation is similar to the one of proposition 2).

If $k \geq k_{6}$, the domestic standard is equal to $\operatorname{Max}\left[\hat{\lambda}_{f}, \tilde{\lambda}_{d}^{*}\right]$ with $\tilde{\lambda}_{d}^{*}$ such that $d \widetilde{W}_{d}\left(\tilde{\lambda}_{d}^{*}\right) / d \lambda=0$. The standard then leads to the exclusion of foreign producers, while the 
international standard $\lambda_{i}{ }^{*}$ allows all producers to offer products if $k_{6} \leq k \leq k_{8}{ }^{4}$ For this latter case, the lower price effect coming from the presence of all producers outweighs the effect of a lower standard $\lambda_{i}^{*}$ compared to the domestic standard favoring a higher equilibrium price. This occurs because of the exclusion of foreign producers and the high standard $\operatorname{Max}\left[\hat{\lambda}_{f}, \tilde{\lambda}_{d}^{*}\right]$.

Exclusion leads to discontinuities in tariff equivalent (see bottom of Figure 5). If $k \geq k_{8}$, both domestic and foreign standards are the same and this leads to the exclusion of foreign producers.

Section 5 underscores the impact of producers' exclusion. In particular, exclusion leads to discontinuities in tariff equivalent and even a shift in the sign of this tariff equivalent when lessefficient domestic producers leave the market (see Figure 4). Note that exclusion emerges even if there is no assumption of fixed cost incurred by sellers. In our model, the crucial point is the cost heterogeneity between domestic and foreign producers leading to the possible exclusion of inefficient producers.

\section{Extensions}

In order to identify and focus on the main economic mechanisms at work, we kept the mathematical aspects as sparse as possible. Our analysis could accommodate various contexts using the following extensions of our model.

1. We did not consider any demand for the foreign country, which is an extreme assumption but corresponds to situations where there is no effective local demand. This

\footnotetext{
${ }^{4}$ The value $k_{6}$ is determined by $d^{2} W_{d}(\lambda) / d \lambda^{2}=0$ with $W_{d}(\lambda)$ given by (5). For $k_{6} \leq k<k_{7}, \hat{\lambda}_{f}$ leads to the highest welfare. The value $k_{7}$ is determined by $\hat{\lambda}_{f}=\tilde{\lambda}_{d}^{*}$, with $d \widetilde{W}_{d}\left(\tilde{\lambda}_{d}^{*}\right) / d \lambda=0$ and $\widetilde{W}_{d}(\lambda)$ given by (11). The value $k_{8}$ is determined by $\widetilde{W}_{d}\left(\tilde{\lambda}_{d}^{*}\right)=W_{i}\left(\lambda_{i}^{*}\right)$ with $W_{i}$ given by (6) with an effort $\lambda_{i}^{*}$.
} 
configuration could be introduced. In this new context, results would be close to results presented in this paper, even if some values of standards or frontiers in figures would change.

2. Throughout the model, we assumed that the external damage is separable from market consumption. However, demand and the external damage can interact when consumers are aware of the damage, for example, via better information provision (Polinsky and Rogerson, 1983) or by abating health effects of pollution with market decisions (Espinosa and Smith, 1995). Again, results would be close to results presented in this paper but with multiple cases, and some values of standards and frontiers in figures would obviously change. This extension leads to multiplicity of cases but with the similar dichotomy of key results of anti-protectionism/protectionism linked to the domestic standard relative to the international one.

3. We abstracted from market power that would arise under a reduced number of firms able to enter the market. This is particularly the case when endogenous sunk costs are linked to firms' effort to reduce expected external damages. Using the notation of section 2, such a sunk cost could be equal to $c \lambda^{2}$ and $\gamma c \lambda^{2}$ but would not depend on output levels selected by producers (a fixed-cost shift rather than a marginal-cost shift). The consequences of a sunk cost for improving safety would be a limited number of firms able to produce and the absence of this cost passed on to consumers in the price. The results under producers' exclusion in section 5 are very close to the results with firms' exit under endogenous sunk cost for improving safety.

4. We assumed a regulatory/inspection cost equal to zero, even if imposing a standard is obviously costly to monitor. Without inspection, the regulator will rarely have as accurate information as the firm with respect to the effort for getting safety. Depending on the cost of firms' inspection, the regulator has to determine the number of inspections for domestic and foreign firms, the penalty for absence of compliance, and the way to finance such a policy. 
Clearly, the social benefits of imposing a standard in the paper would be diminished by taking into account the cost of regulation and would lead to lower standards.

5. The cost heterogeneity defined by $\gamma$ was linked to the effort/standard choice. An alternative assumption could also consider additional cost heterogeneity among countries linked to other factors, such as the labor cost. Such a type of heterogeneity could reinforce the exclusion of producers with a high labor cost, for instance, with similar mechanisms to the ones presented in section 5 .

6. Throughout the model, we assumed that the regulator was acting in the public's best interest. One stumbling block for such regulatory optimality is the efficiency of the public regulatory authority itself. Public agencies may be "doomed" if either (i) their mandate is not clearly defined, (ii) they suffer from excessive bureaucracy, or (iii) the industrial lobby’s influence creates lax regulation. A regulator may sometimes choose more than the necessary amount of regulation with a very large standard, depending on the incumbent's influences upon the agency. Kim (1997) underscores how regulation is suboptimal when an incumbent behaves strategically against the government (the regulator, as a follower, deters entry by newcomers, protecting the incumbent's oligopoly situation), an aspect we did not consider here. This raises the question of lobbying by the domestic firm, as in Fisher and Serra (2000).

7. Government regulation is not the only approach deserving consideration, with measures ranging from voluntary practice, codes of good conduct, "private” standard, and market incentives as reputation mechanisms or quality/safety signaling. One extension that is of interest concerns that of a voluntary standard/certification system in which each firm decides whether or not to comply with the standard. This question is particularly important in an international context, where supermarkets impose higher safety standards for food to developing countries 
compared to the ones defined by countries or international organizations like the Codex Alimentarius (Henson and Reardon, 2005).

\section{Conclusions}

Using a sparse framework, various mechanisms were elucidated by which domestic and international contexts may influence the provision of a product’s environment/safety via a standard. This stylized framework made it possible to infer some essential economic mechanisms that are valid in various realistic situations.

By focusing on safety and trade, the paper led to new results. We showed that a standard can be anti-protectionist, which is the case when foreign producers are much more efficient than domestic producers. Clearly, the difference between both standards depends on the relative efficiency of domestic and foreign producers. We also showed that protectionism could emerge without a protectionist motive when domestic producers are excluded from the market because they are unable to meet the standard although foreign producers can meet the standard.

We also showed that a tariff equivalent related to the impact of standard choices in equilibrium price may be positive or negative, since domestic and foreign choices differ. Heterogeneity matters a lot in the characterization of the sign of tariff equivalents. Eventually, when exclusion may occur for relatively high values of standards, a tariff equivalent may change signs when exclusion occurs (see section 5).

These results have consequences for empirical evaluations of NTB in sensitive sectors such as food industries or services. The general approach of comparing the domestic price and the world price without a reference to an international standard is likely to be flawed. Moreover, 
any such measure of a tariff equivalent that further abstracts from producers' heterogeneity in meeting the standard is likely to be flawed.

This model suggests that it is especially imperative for governments to examine not only the safety regulations imposed upon an industry but also market and competitive structure (including the firms' profitability influencing the exit/entry). These results mean that a regulator or the WTO should also focus on competitive structures and market mechanisms, and not only on risk assessment, when a domestic standard differs from the international standard. 


\section{References}

Baldwin, R.E. 1970. Nontariff Distortions of International Trade. Washington, DC: The Brookings Institution.

Barrett, S. 1994. Strategic Environmental Policy and International Trade. Journal of Public Economics 54: 325-338.

Beghin, J.C., and J.C. Bureau. 2001. Quantitative Policy Analysis of Sanitary Phytosanitary and Technical Barriers to Trade. Economie Internationale 87: 107-130.

Boom, A. 1995. Asymmetric International Minimum Quality Standards and Vertical Differentiation. Journal of Industrial Economics 18: 101-120.

Bureau, J.C., S. Marette, and A. Schiavina. 1998. Non-Tariff Trade Barriers and Consumers’ Information: The Case of the EU-US Trade Dispute over Beef. European Review of Agricultural Economics 25 (4): 437-462.

Chambers, R.G., and M. Weiss. 1992. Revisiting Minimum Quality Standards. Economic Letters 40: 197-201.

Das, S., and S. Donnenfeld. 1987. Trade Policy and Its Impact on the Quality of Imports. Journal of International Economics 23: 77-95.

Das, S., and S. Donnenfeld. 1989. Oligopolistic Competition and International Trade: Quantity and Quality Restrictions. Journal of International Economics 27: 299-318.

Deardorff, A. V., and R. M. Stern. 1998. Measurement of Nontariff Barriers. Ann Arbor, MI: The University of Michigan Press.

Dee, P., and M. Ferrantino, eds. 2005. Quantitative Methods for Assessing the effects of NonTariff Measures and Trade Facilitation. Singapore: APEC Secretariat and World Scientific Publishing Co. 
EC. 2006. European Sky Protected Against Unsafe Airlines, Press Release IP/06/359, March 22, European Commission, Brussels, http://europa.eu/rapid/pressReleasesAction.do?reference=IP/06/359\&format=HTML\&aged=0\&language=EN\& guiLanguage=en\#fn1 (available May 2007).

Espinosa, J.A., and V.K. Smith. 1995. Measuring the Environmental Consequences of Trade Policy: A Nonmarket CGE Analysis. American Journal of Agricultural Economics 77: 772777.

Fisher, R., and P. Serra. 2000. Standards and Protection. Journal of International Economics 52: $377-400$.

Freeman, A.M. 2003. The Measurement of Environmental and Resource Values: Theory and Methods, second edition. Washington, DC: RFF Press.

Henson, S., and T. Reardon. 2005. Private Agri-Food Standards: Implications for Food Policy and the Agri-Food System. Food Policy 30: 241-253

Henson, S., and J. S. Wilson, eds. 2005. The WTO and Technical Barriers to Trade. Critical Perspectives on the Global Trading System and the WTO series, Northampton, MA: Edward Elgar Publishing.

Kim, J. 1997. Inefficiency of Subgame Optimal Entry Regulation. Rand Journal of Economics 28: 25-36.

Polinsky, A., and W. Rogerson. 1983. Products Liability and Consumer Misperceptions and Market Power. Bell Journal of Economics 14: 581-89.

Sturm, D.M. 2006. Product Standards, Trade Disputes, and Protectionism. Canadian Journal of Economics 39 (2): 564-581.

Tian, H. 2003. Eco-Labelling Scheme, Environmental Protection, and Protectionism. Canadian Journal of Economics 36 (3): 708-725. 
Yue, C., J.C. Beghin, and H.H. Jensen. 2006. Tariff Equivalent of technical Barriers to Trade with Imperfect substitution and Trade Costs. American Journal of Agricultural Economics 88 (4): 947-960. 


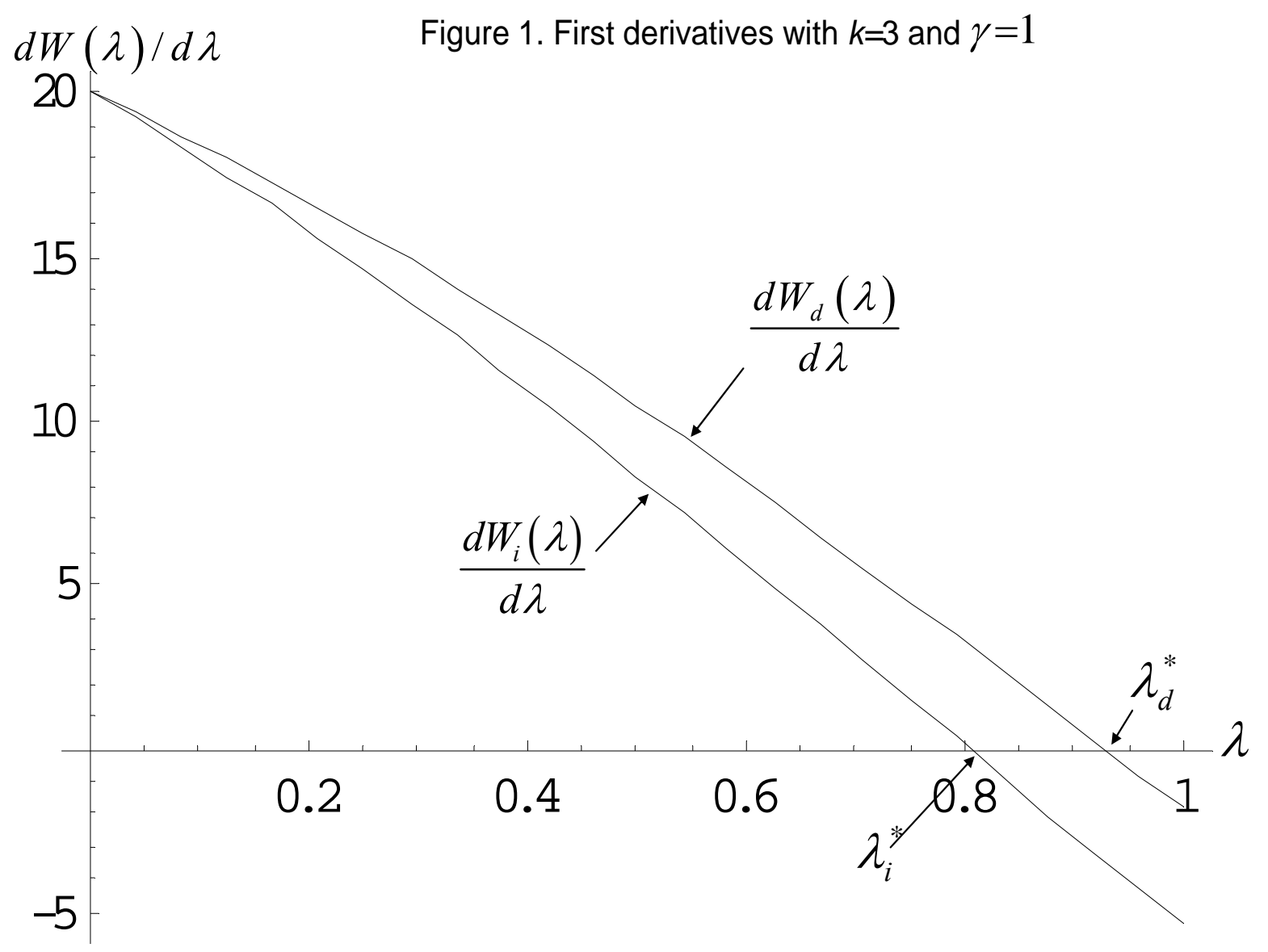


Figure 2. Socially optimal efforts and tariff equivalent with $\gamma=1 / 4$

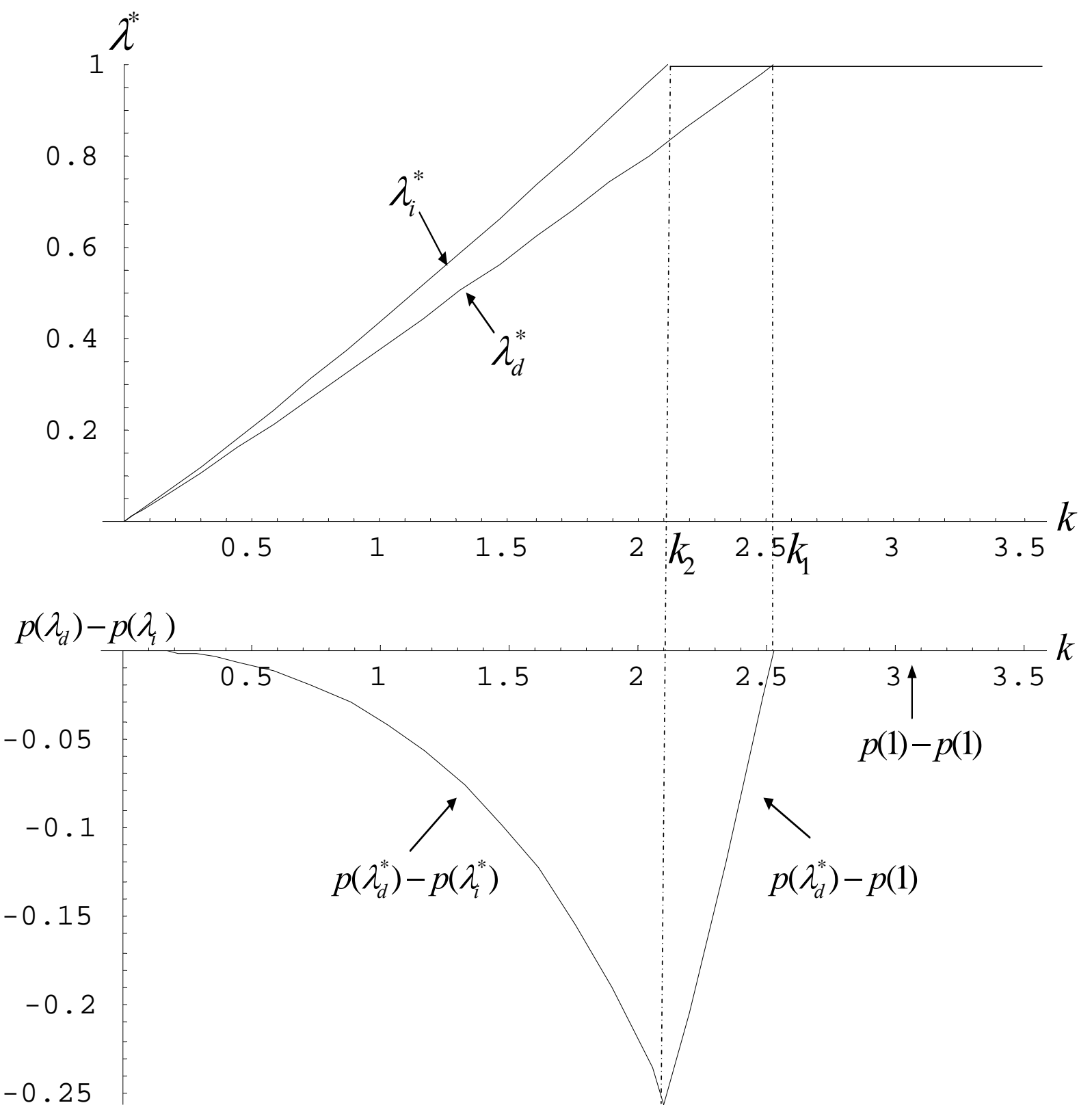




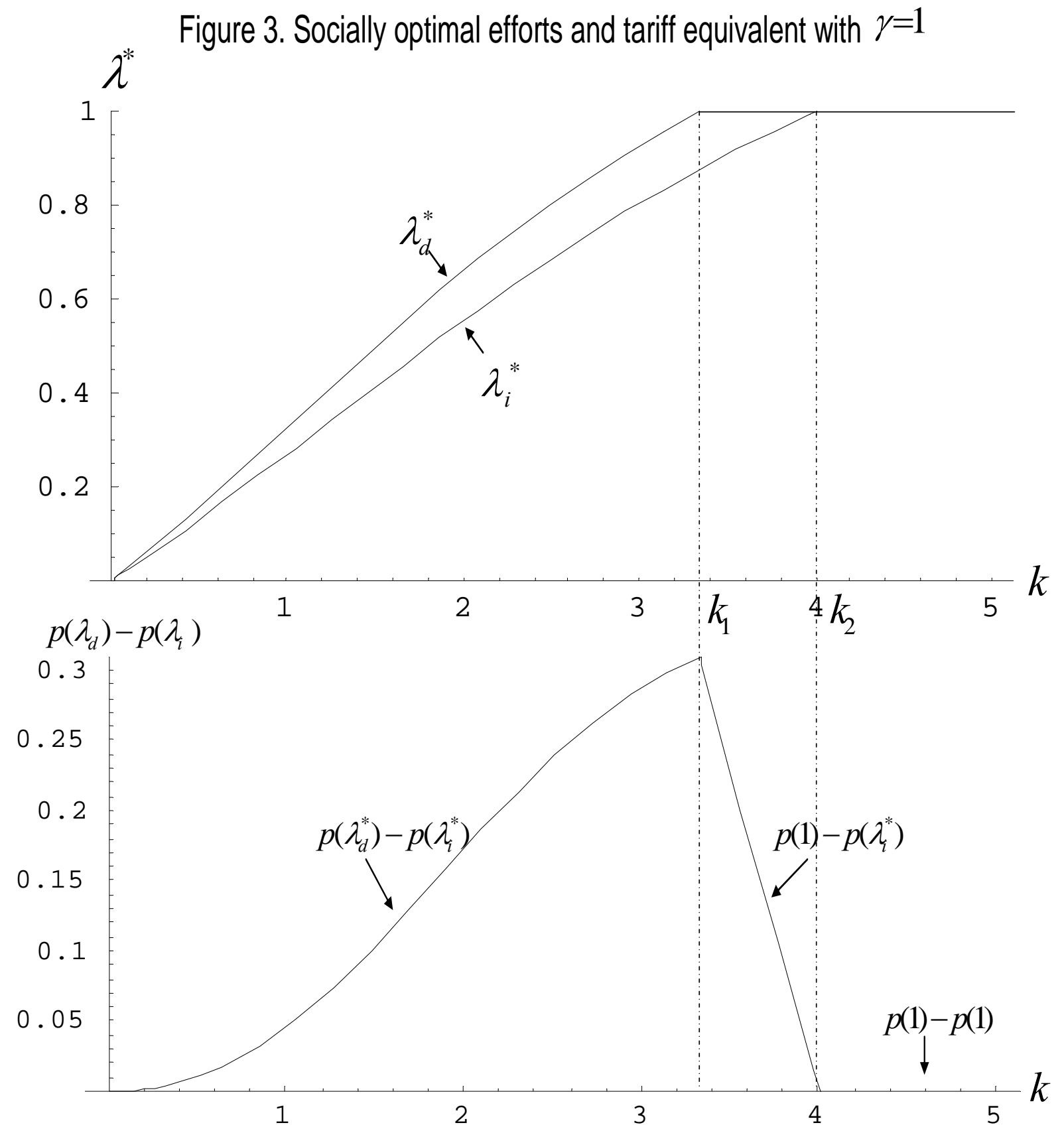




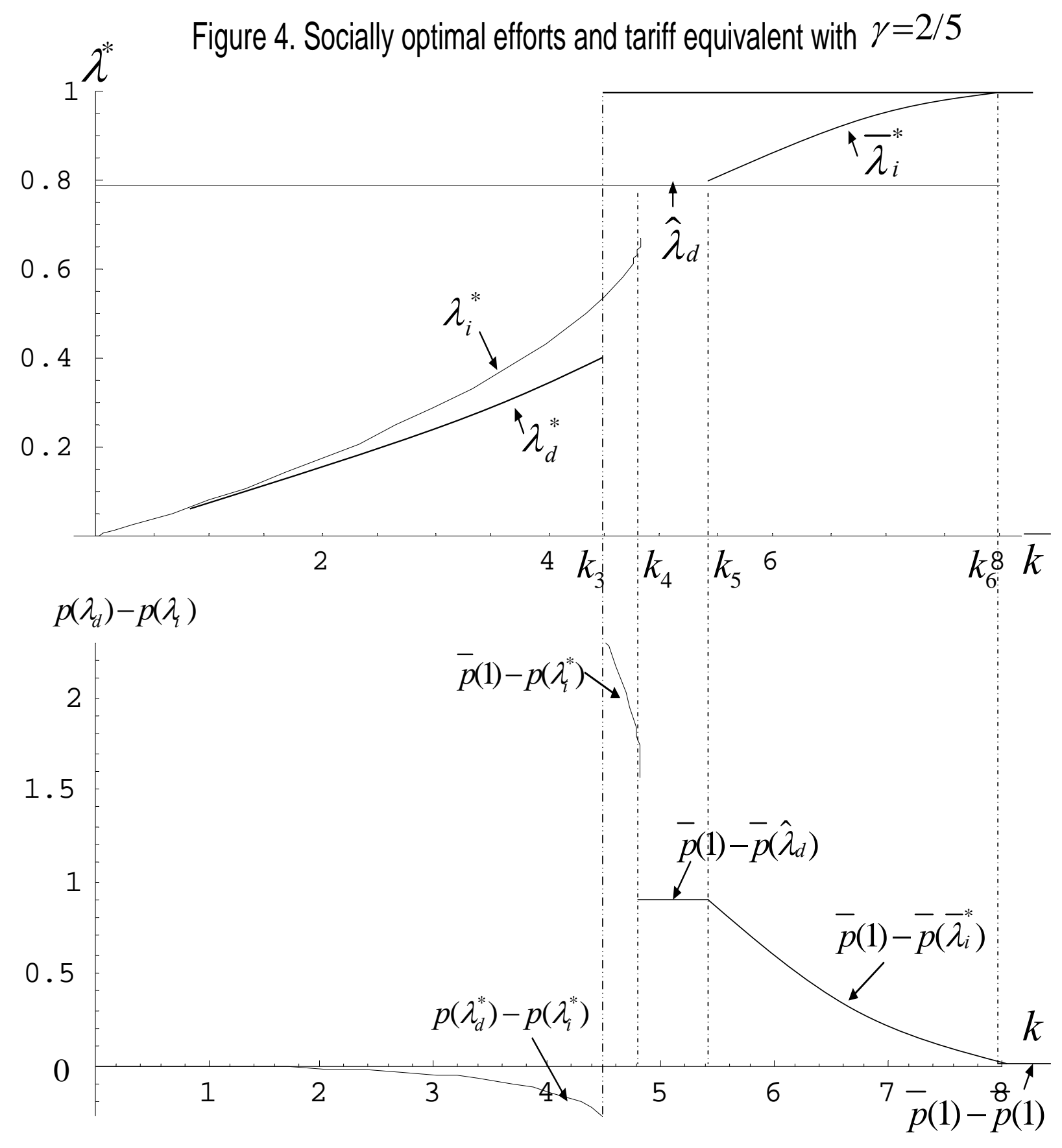


Figure 5. Socially optimal efforts and tariff equivalent with $\gamma=15 / 2$
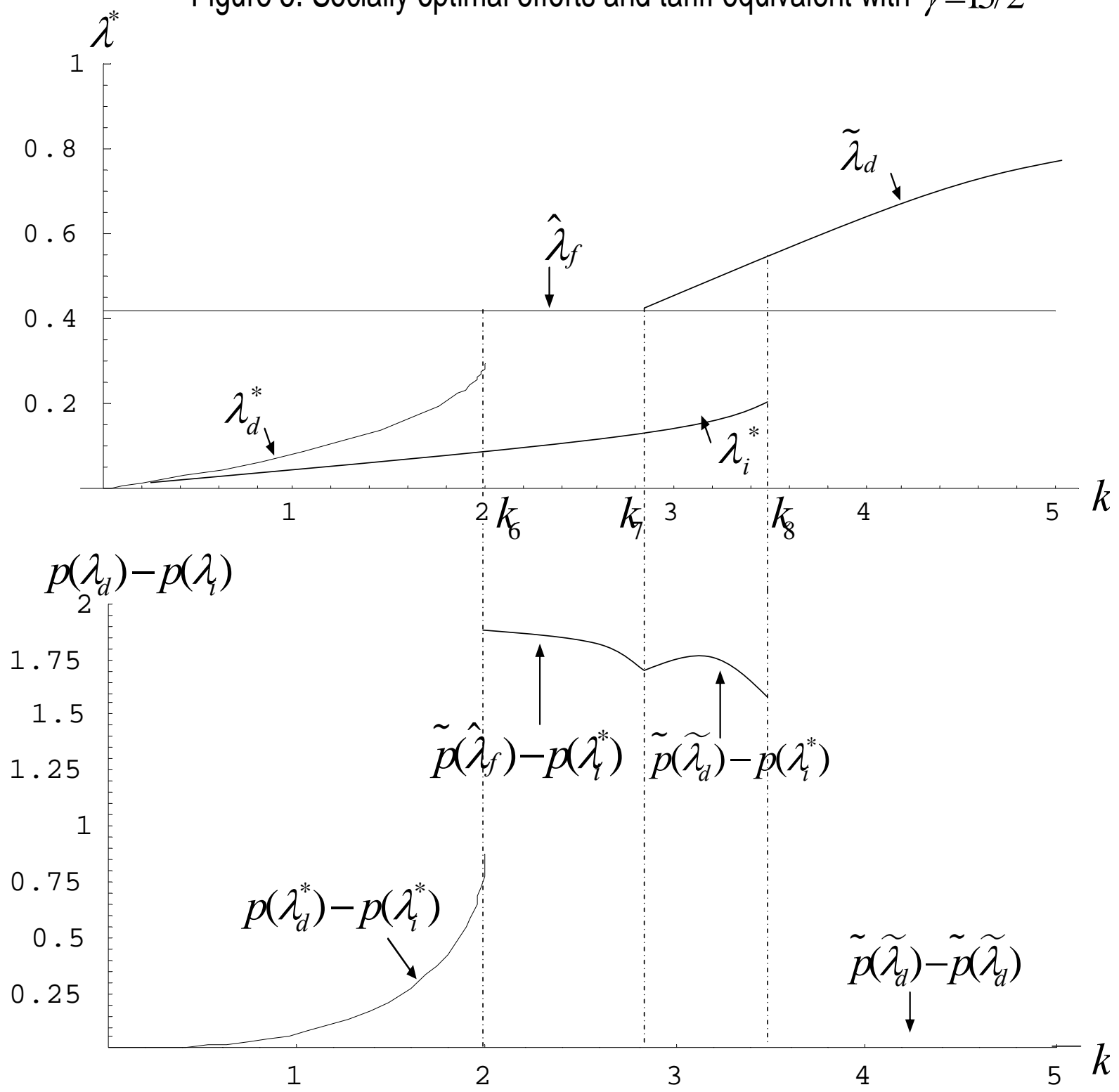